\title{
Repellent Solution Precise Application to Cotton Clothes Surrounding Mango Trunk Trees to Avoid Ant Climbing
}

Federico Hahn*

Irrigation Department, Universidad Autonoma Chapingo, Mexico
ISSN: 2637-7659

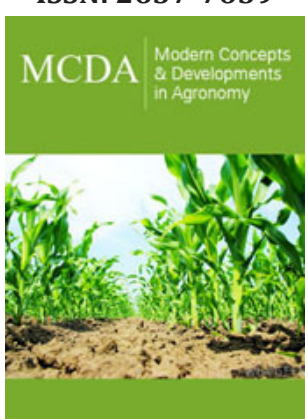

*Corresponding author: Federico Hahn, Irrigation Department, Universidad Autonoma Chapingo, Mexico

Submission: 泟 November 10, 2020

Published: 眥December 02, 2020

Volume 7 - Issue 4

How to cite this article: Federico Hahn. Repellent Solution Precise Application to Cotton Clothes Surrounding Mango Trunk Trees to Avoid Ant Climbing. Mod Concep Dev Agrono. 7(4). MCDA. 000668. 2020. DOI: $10.31031 /$ MCDA.2020.07.000668

Copyright@ Federico Hahn, This article is distributed under the terms of the Creative Commons Attribution 4.0 International License, which permits unrestricted use and redistribution provided that the original author and source are credited.

\begin{abstract}
Leaf-cutting ants (Atta cephalotes) cause production losses to mango producers since they take down inflorescences and tender leaves. A repellent fluid was sprayed to an absorbent cloth placed around the tree-trunk to prevent ants from climbing. Eucalyptus oil-water emulsion was manually sprayed into the cotton fabric surrounding the tree trunks and the effect of fabric evaporation analyzed when it was covered or exposed directly to the environment. Manual application of the repellent solution is labour-intensive as each hectare has at least 100 trees. Precise spraying of hundreds of tree fabrics can be done with the orchard irrigation system. Relative humidity measurements were obtained every 3 hours comparing clothes moistened by drip or sprinkler irrigation systems, being the latter more homogeneous. Drippers together with tubing provide better cloth wetting, but the fabric should be thinner. Aroma was sampled by a group of experts and the oil-water emulsion should be applied every two days.
\end{abstract}

Keywords: Precise spraying;Oil-water emulsion;Ant control; RH fabric drying

\section{Introduction}

Worker ants follow trails towards foraging sites where they cut leaves, flowers and buds in fragments. Ants return to their nest with the food collected after establishing bidirectional trails between the nest and the food source. In a study at Brazil, $16.6 \%$ of the total coffee plants was attacked by Atta sexdens rubropilosa and 1\% was defoliated causing production losses [1]. Changes in ant walking speed are also caused by meteorological conditions such as temperature, rain [2] and wind [3].

Precise spraying in agriculture have been studied during this century [4,5]. Timely and accurate precise spraying in orchards and nurseries reduce pesticide residues, saving manpower and material resources [4]. Canopy size and density measured by laser scanning sensors, ultrasound and LIDAR [5] show high variations within orchards.

Some plant extracts repel leaf-cutting ants [6]. Essential oils are composed of complex mixtures of various chemical components including terpenes and repel insect herbivores [7]. Essential oils are degraded rapidly by the environment, being sensitive to oxygen, light and high temperature. In laboratory experiments, concentrations doses over $1 \%$ tea tree oil repelled ants, lasting its repellent effect up to four days [8]. Mango growers use microsprinklers instead of drippers to produce mulch and cover plants over the orchard floor. Drippers are more water-efficient than sprinklers due to reduced evaporative losses at the soil surface or to direct evaporation of water in the air prior to soil contact [9]. The amount of water that evaporates while water droplets travel from the nozzle to the crop canopy is considerable [10].

Mango orchards suffer up to 30\% production losses during the dry season when ants attack tree inflorescences and leaves. CEMANGO a government agency searching to increase mango yield, supported the elaboration and evaluation of a prototype to avoid leaf-cutting ants attacks. Previous laboratory experiments found that an essential oil emulsion applied to a cloth wrapped around the tree trunk decreased ant climbing. In this paper, fabric $\mathrm{RH}$ was monitored several hours after liquid application to determine its drying rate; a group of experts analyzed aroma decay with time. New precise wetting techniques to apply 
simultaneously a liquid emulsion to a fabric surrounding the trunk of 100 trees with the use of mango orchard irrigation systems were developed and evaluated.

\section{Material and Methods}

Different prototypes were installed in fifteen-year-old trees where Atta cephalotes ants forage during the night. Mature ant colonies within the orchard contain $10^{5}$ workers approximately, and forage at mango trees, $30 \mathrm{~m}$ away from their nest. The mango orchard located at Loma Bonita, Guerrero (17² $25^{\prime} 47^{\prime \prime} \mathrm{N},-101^{\circ} 11^{\prime}$ $19^{\prime \prime}$ W, 17m ASL) has an automated irrigation system.

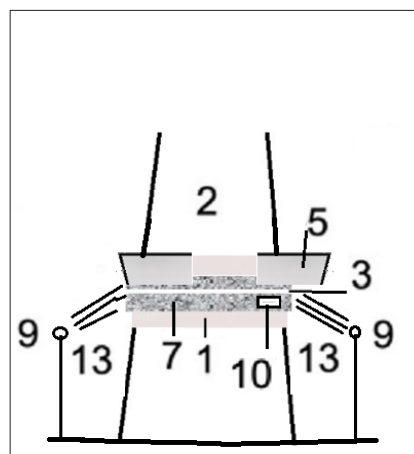

(a)

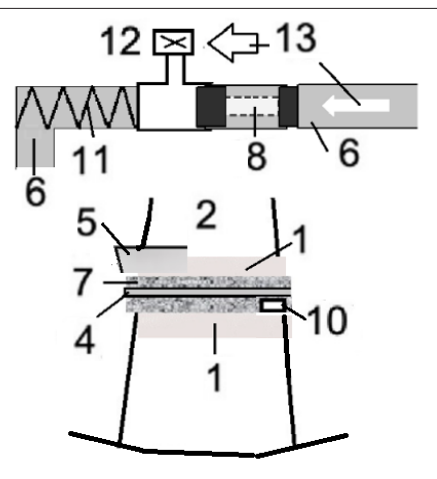

(b)
Figure 1: Developed prototypes with

(a) simple cloth, sprinklers, data logger and repellent system, and

(b) hose having integrated drips connected to irrigation system; consisting of

(1) polyethylene plastic,

(2) trunk,

(3) plastic strap,

(4) hose with integrated drips,

(5) plastic cover,

(6) hose,

(7) absorbent cloth,

(8) piston,

(9) micro-sprinklers,

(10) RH sensor and data logger,

(11) return spring,

(12) solenoid control valve, and

(13) water flow direction.

A prototype patented by Hahn (2020) avoided ants from climbing tree trunks (2; Figure 1). It had a galvanized sheet that holds a plastic container (5; Figure 1), a hose (6; Figure 1) and several micro-sprinklers (9; Figure 1). Water enters the system through a 24 VDC solenoid valve (mod VXE2120-02F-5DO, SMC, USA) connected to the irrigation system (12; Figure 1). Water gets mixed with the pure repellent solution (13; Figure 1) using a venturi and the resultant solution flows toward the hose surrounding the tree trunk. A sensor (10; Figure 1) monitors the relative humidity nearby the cotton cloth every 30 minutes and stores it in a data logger (Novus, USA). The relative humidity sensor (model HIH4000 , Honeywell, USA) is made of a thermoset polymer capacitor that increases its voltage output linearly with RH.

Wicking represents the capillary movement of moisture within the cloth. As fabric thickness determines how much water can be absorbed, a $4 \mathrm{~mm}$ thick cotton cloth was selected, being its drying time of 12 hours. A 15-year-old tree has a trunk diameter of $40 \mathrm{~cm}$ and if the cotton fabric used is $10 \mathrm{~cm}$ wide and $4 \mathrm{~mm}$ thick, the cotton cloth weights $86 \mathrm{~g}$. If the fabric is introduced into a water tank, its weight increases to $387 \mathrm{gr}$, caused by the absorption of $300 \mathrm{ml}$ of water.

In the two experiments the applied emulsion had a $10 \%$ of eucalyptus essential oil mixed with $200 \mathrm{ml}$ of water. To perform the treatments, a $10 \%(\mathrm{v} / \mathrm{v})$ solution $(10 \%$ essential oil, $88 \%$ water, $2 \%$ Tween 20, Merck) was prepared. On the first experiment the water in oil emulsion [11] was applied with the micro-sprinklers to the cotton cloth surrounding 50 tree trunks. The odor was classified as very strong, strong, medium, just detectable and none. Sampling was taken every 3 hours during two entire days. In the second experiment, a hose (6; Figure 1) with integrated drips was surrounded by the cloth and fixed to each trunk with a plastic strap. After filling the hose and closing the valve, a piston (8; Figure 1) pushed the essential oil solution to the dripping hose, getting the cloth wet; The piston is driven hydraulically by the pumped water. Once the irrigation pump stops, a spring (11; Figure 1) returns the piston to its starting position.

\section{Result}

In the first experiment, manual spraying of the 50 tree cloths was very laborious and took over 90 minutes. Relative humidity of the thin cloth fixed around the trunk decreased to $91.1 \pm 1.05 \%$ at 8:00 next day, twelve hours after manual spraying (Figure 2).

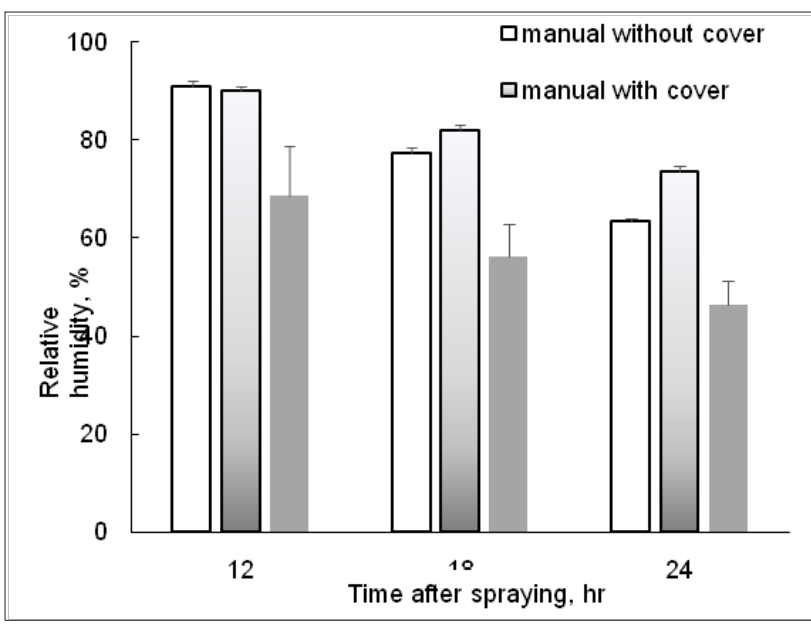

Figure 2: Relative humidity of fifty thin clothes 12,18 and 24 hours after spraying them manually with and without cover and after sprinkling them. 
Cloth wetness decreased slowly during the first 12 hours at night being the water lost between 5-6\%. Six hours later at $14: 00$, the uncovered cloth, reduced its moisture to $77.5 \pm 1.15 \%$, meanwhile the covered clothes remained humid at $82.1 \pm 1.1 \%$. The cloth without cover presented a RH of $63.3 \pm 0.6 \%$ at 20:00, meanwhile the covered cloth remained wet at $73.7 \pm 0.34 \%$ at this time; standard deviation in all the cases was close to 1 .

In trunks having a plastic container covering the manual sprayed cloth, aroma remained constant during the first ten hours as shown by the thick continuous line in Figure 3. Eighty percent of the trees remained with a strong odor after 15 hours. When the pointed line intercepts the dark continuous line, the aroma tends to decrease and the panel of experts considered it medium, peaking after 24 hours.

Half of the trees presented a just detectable fragrance after 27 hours (Figure 3). After 40 hours, $50 \%$ of the trees did not present any odor, and after 48 hours, aroma was absent in all the fabrics surrounding the trunks.

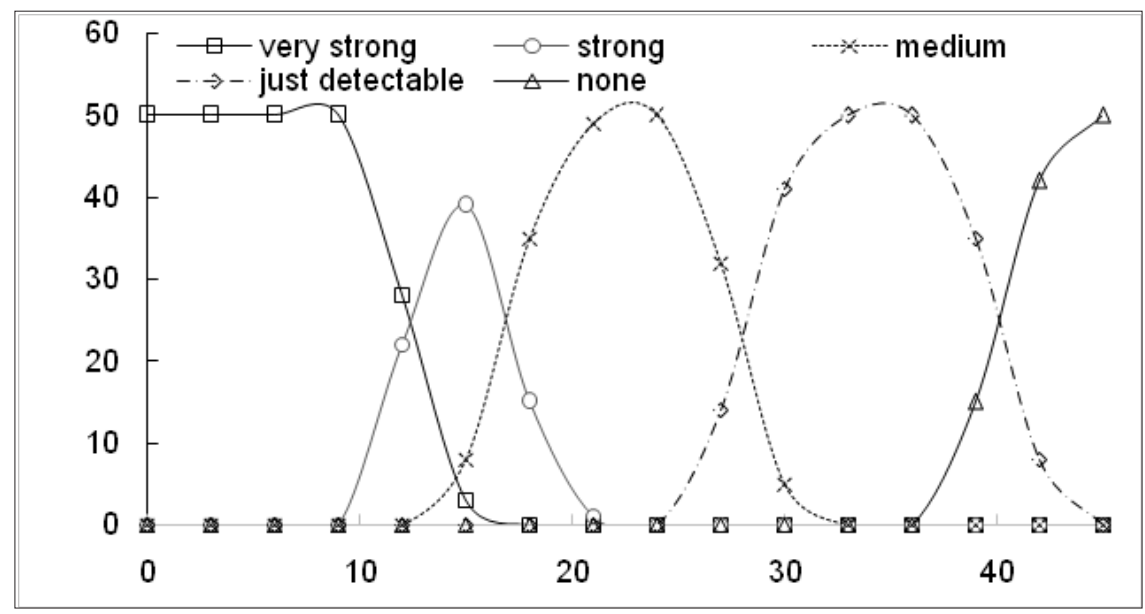

Figure 3: Aroma remaining in a plastic covered cloth after several hours of application.

In the integrated drippers experiment, the drippers are $5 \mathrm{~cm}$ apart, but the liquid wet the fabric every $2.5 \mathrm{~cm}$ (Figure 4 ) as the hose turned twice around the trunk. As roselle was used as colorant it was easy to detect the wet section of the fabric. A peak was found every $2.5 \mathrm{~cm}$ and only the fabric bottom was wet. If only a liter of water was applied by the drippers, $50 \pm 3.2 \%$ moisture peaks were monitored on the fabric (Figure 4); $88 \pm 2.2 \%$ moisture peaks were measured after applying 5 liters by the hose. In Figure 4, the cotton fabric was dry at a $7.5 \mathrm{~cm}$ linear distance as the dripper clogged. It was found that after 24 hours the aroma in all clothes was absent.

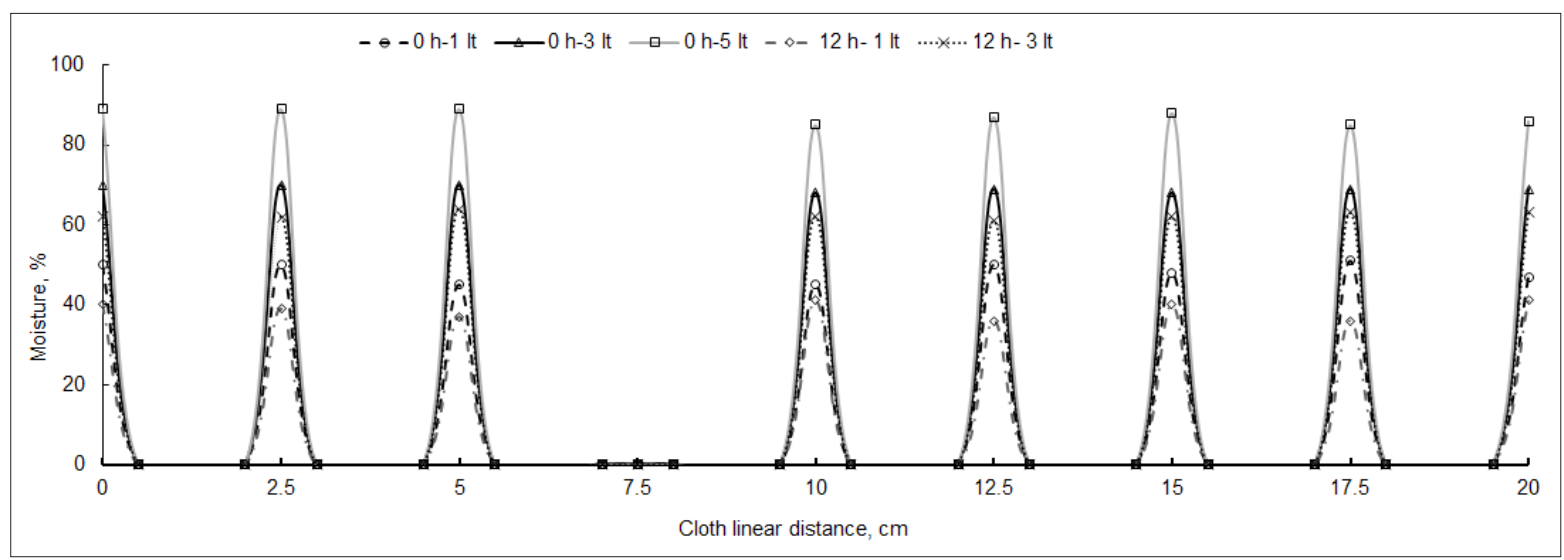

Figure 4: Linear cloth periodic HR caused by drippers applying different flows.

\section{Conclusion}

This study compared precise spraying techniques that were connected to the existing irrigation systems to spray simultaneously several hectare of trees. The aroma of the repellent solution applied to the cloth surrounding the tree trunk should be kept as long as possible, so fabric drying was fundamental. In the precise spraying techniques, the fabric lost its odor-fragrance after 2 days. Fabric wetness status was monitored non-intrusively providing cloth moisture. 
As manual application of the repellent solution is labourintensive, spraying the cloth of 100 trees simultaneously was done by using a pressurized irrigation system; some additional elements were added to moist the fabric clothes. After comparing the results of drip and micro-sprinkler application it was clear that cloth water absorption differed, being water spraying more homogeneous. During the first application of water on dry-new clothes, water impregnates totally in both systems. In the hose dripping system, the fabric is first wetted in the inner surface close to the trunk, meanwhile in the sprinkler system the liquid penetrates the fabric from the outer surface to the interior. When the fabric is covered, a lower quantity of solution (approx. 20\%) arrives to the cloth, being the application very inefficient and expensive, but the aroma and fabric moisture lasts longer. If the liquid that requires the cloth is $300 \mathrm{ml}$, a total of $1500 \mathrm{ml}$ have to be applied. When no cover is present with a sprinkler-droplet $40 \%$ of efficiency, $750 \mathrm{ml}$ of liquid is required per tree. It would be advisable to cover only $50 \%$ of the fabric and use a deflector to reduce evapotranspiration. In future fabric designs, nanoparticles and new technologies can be used to release the essential oil more slowly.

\section{Acknowledgement}

I would like to acknowledge CEMANGO who fund this project.

\section{References}

1. Varon EH, Eigenbrode SD, Bosque Pérez NA, Hilje L (2007) Effect of farm diversity on harvesting of coffee leaves by the leaf-cutting ant Atta cephalotes. Agricultural and Forest Entomology 9(1): 47-55.
2. Farji Brener A, Dalton M, Balza U, Courtis A, Lemus I, et al. (2018) Working in the rain? Why leaf-cutting ants stop foraging when it's raining. Insectes Sociaux 65: 233-239.

3. Alma A, Farji Brener A, Elizalde L (2016) Gone with the Wind: Short- and long-term responses of leaf-cutting ants to the negative effect of wind on their foraging activity. Behavioral Ecology 27(4): 1017-1024.

4. Dou H, Zhang C, Li L, Hao G, Ding B, et al. (2018) Application of variable spray technology in agriculture. IOP Conference Series: Earth and Environmental Science 186: 012007.

5. Llorens J, Gil E, Llop J, Escolà A (2011) Ultrasonic and LIDAR sensors for electronic canopy characterization in vineyards: advances to improve pesticide application methods. Sensors 11(2): 2177-2194.

6. Rocha AG, Oliveira BMS, Melo CR, Sampaio TS, Blank AF, et al. (2018) Lethal effect and behavioral responses of leaf-cutting ants to essential oil of Pogostemon cablin (Lamiaceae) and its nanoformulation. Neotrop Entomol 47(6): 769-799.

7. Regnault Roger C, Vincent C, Arnason JT (2012) Essential oils in insect control: low-risk products in a high-stakes world. Annu Rev Entomol 57: 405-424.

8. Buteler M, Alma A, Herrera M, Gorosito N, Fernández P (2019) Novel organic repellent for leaf-cutting ants: tea tree oil and its potential use as a management tool. International Journal of Pest Management pp. 1-9.

9. El Attar H, Merwad M, Mostafa E, Saleh M (2019) Yield, fruit quality and leaf mineral content of mango trees as affected by subsurface drip irrigation system. Bioscience Research 16(1): 620-628.

10. McLean R, Sri Ranjan R, Klassen G (2000) Spray evaporation losses from sprinkler irrigation systems. Canadian Agricultural Engineering 42(1): $1-8$.

11. Rasheed SL, Rasheed AS (2017) Formulation of essential oil pesticides technology and their application. Agri Res \& Tech J 9(2): 555759. 